\title{
A GREAT DAY SPENT WITH COLLEAGUES
}

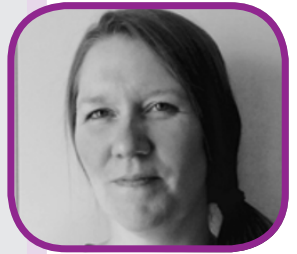

Reader panel

member Nicola

Sherlock reports

back from $B D A$

Conference

So, I'm back from

attending this year's
Oral Health Foundation, and the British Society of Dental Hygiene and Therapy for guidance, advice or simply to put faces to names.

On reflection, this was a great day spent with colleagues, held at the perfect location (I live in Manchester) and there was a great

'YES, WE GOT A LOT OF "FREE STUFF", BUT

WHAT IS EVIDENT IS THAT I HAVE

ENOUGH CPD READING MATERIAL AND LINKS

FOR ONLINE VERIFIABLE CPD TO SEE ME

THROUGH TO THE NEXT CYCLE.'

British Dental Conference and Exhibition with sore feet and aching shoulders from carrying bags loaded with everything from toothpaste samples to champagne stoppers (not sure I'll use the latter as once my prosecco is open I can't think why I'd seal it again!).

Demonstrating the dental profession's move into the ever-online world, there was a big focus this year on technology and social media presence, particularly smart phone apps (BPE scoring apps, a guide to acid wear app, patient education apps, interactive lectures and even an app to navigate the conference and exhibition) and these may be tools I look at using in the future to help pass guidance and information on to patients and their parents/support teams.

Prevention and sugar were the main themes on the BDA stand and attendees could take the 'Sugar Shock Test' to determine amounts of sugar in popular drinks (something dental nurses preach to patients and parents on a daily basis).

There were stalls where you could try out new flavours of mouthwash, stalls demonstrating new designs of interdental cleaning aids, and even a wheel-of-fortune offering spa breaks as the big win (I won a book and was made-up!). Representatives could be sought out from many of the main dental societies and associations such as the British Association of Dental Nurses, the atmosphere. Yes, we got a lot of 'free stuff', but sat on the living room floor sorting through it all, what is evident is that apart from what I gained in just attending the event and the seminars available there, I have enough CPD reading material and links for online verifiable CPD to see me through to the next cycle.

I have flyers and information for further education and extended duties courses, I networked with some great people and got contact numbers for agencies and companies who are currently recruiting for UK/overseas volunteering experiences and gained information-galore on lots of new products, some of which will be of great benefit to the special care patients we see at my clinic.

Dental nurses should not be put off that the Conference seems mainly geared towards dentists and should view the event as a way to increase their knowledge and skills, to network with like-minded professionals and gain large swathes of $\mathrm{CPD}$ all in one day.

\section{Nicola Sherlock RDN}

Do you have an opinion on something published in BDJ Team or on working in the dental industry? Do you need advice from an expert that we might be able to help you with? Just email bdjteam@nature.com Letters may be edited for space. Opinions expressed do not necessarily reflect those of the editorial team or the publishers 